\title{
PEMBERIAN ACTIVE STRETCHING PERGELANGAN TANGAN MENGURANGI KELUHAN CARPAL TUNNEL SYNDROME PADA PEKERJA PANDAI BESI DI DESA SIDAN KABUPATEN GIANYAR
}

\author{
IP Darmawijaya, Luh Pande Putu Novita Yani, Agung Wahyu Permadi \\ Program Studi Fisioterapi \\ Fakultas Ilmu Kesehatan Sains dan Teknologi Universitas Dhyana Pura Bali \\ Email: darmawijaya@undhirabali.ac.id
}

\begin{abstract}
ABSTRAK
Pekerja pandai besi bekerja menggunakan tangan dan pergelangan tangan secara aktif menggenggam alat yang digunakan saat bekerja, menempa besi secara berulang-ulang mengalami keluhan akibat kerja menjadi faktor risiko timbulnya Carpal Tunnel Syndrome. Keluhan yang terjadi berupa nyeri yang dapat mempengaruhi aktifitas pekerja pandai besi. Untuk mengurangi adanya keluhan nyeri dapat diberikan active stretching pergelangan tangan. Rancangan penelitian yang diterapkan pada penelitian ini adalah preeksperimental dengan one group pretest-postest design. Sampel yang menjadi subyek penelitian berjumlah 15 orang. Analisis penelitian ini menggunakan uji t berpasangan (paired t-test). Hasil uji mendapatkan nilai signifikan 0,000 yang artinya $0,000<0,05$, jadi dapat disimpulkan bahwa pemberian active stretching pergelangan tangan mengurangi keluhan nyeri Carpal Tunnel Syndrome pada pekerja pandai besi di Desa Sidan Kabupaten Gianyar.
\end{abstract}

Kata Kunci: pekerja pandai besi, Carpal Tunnel Syndrome, aktif stretching

\begin{abstract}
The blacksmith actively use their hand and wrist to grab the tools when working, forging iron repeatedly can experience work complaints that may causes the risk factor of Carpal Tunnel Syndrome. The Pathology of Carpal Tunnel Syndrome actually can be done by preventive action that is active stretching wrist exercise. The research design applied in this study ispre-experimental with of One Group Pretest-Posttest Design. The sample in this study amounted to 15 people. The analysis of this study used paired t-test. The study resulted significant value 0.000 which means $0.000<0,05$, so it can be concluded that given active wrist stretching can reduce the symptom of carpal tunnel syndrome in blacksmith at Sidan village Gianyar regency.
\end{abstract}

Keyword: Blacksmith, carpal tunnel syndrome, active stretching

\section{PENDAHULUAN}

Kabupaten Gianyar sering ditempatkan sebagai wilayah yang menyimpan sumber inspirasi pengembangan seni budaya salah satunya di Desa Sidan Kabupaten Gianyar yaitu pekerja pandai besi yang merupakan suatu kegiatan kerja usaha produksi yang menghasilkan peralatan dari pengolahan besi.

Pekerja pandai besi dalam melakukan pekerjaannya masih menggunakan peralatan dan cara kerja secara tradisional. Produk yang dihasilkan salah satunya adalah pisau blakas yaitu pisau besar khas Bali. Proses pembuatan pisau blakas dimulai dari pemanasan bahan dari per mobil bekas dalam tungku, menempa besi yang sudah dipanaskan, memegang besi dengan bantuan penjepit saat dibentuk, memegang besi saat menggerinda untuk penghalusan bahan dan pemasangan gagang untuk pegangan pisau blakas. Dari pembuatan pisau blakas proses menempa paling penting dan banyak membutuhkan tenaga dan genggaman yang kuat pada tangan. Gerakan menempa dengan gerakan menekuk (fleksi) dan gerakan meluruskan (ekstensi) lengan dan pergelangan tangan serta genggaman yang kuat pada tangan memegang palu secara berulang berpotensi terhadap getaran menyeluruh pada tubuh. Getaran yang terjadi pada tubuh yang berlangsung lama ditandai dengan adanya tremor, kekakuan, kesulitan mengambil dan menggenggam benda kecil (Rina, 2010). Getaran langsung pada tangan akan berdampak pada meningkatnya kontraksi otot (Suma'mur, 2014). Bila otot berkontraksi maka timbul suatu kerja yang memerlukan energi. ATP (adenosin trifosfat) adalah sumber energi untuk kontraksi (Syaifuddin, 2013).

Kontraksi kuat otot yang berlangsung lama mengakibatkan keadaan kelelahan otot akibat ketidakmampuan proses kontraksi dan metabolisme serabut otot untuk melanjutkan suplai pengeluaran kerja yang sama. Saraf terus menerus bekerja dengan baik, impuls saraf berjalan normal melalui hubungan otot dan saraf masuk ke dalam serabut otot. Potensial aksi normal menyebar ke serabutserabut otot, tetapi kontraksi makin lama makin 
lemah karena dalam serabut otot kekurangan ATP. Hambatan aliran darah yang menuju otot yang sedang berkontraksi mengakibatkan kelelahan otot yang hampir sempurna dalam waktu kurang dari 1 menit karena kehilangan suplai zat gizi terutama kehilangan oksigen (Guyton, 2011).

Pekerjaan yang monoton dan gerakan yang berulang akan menyebabkan pembengkakan sarung tendon sehingga menimbulkan tekanan pada tendon pergelangan tangan. Jika kontraksi otot melebihi 20\% maka peredaran darah ke otot berkurang menurut tingkat kontraksi yang dipengaruhi oleh besarnya tenaga yang diperlukan. Suplai oksigen ke otot menurun, kerja saraf yang menginervasi otot-otot terganggu, proses metabolisme terhambat akibatnya terjadi penimbunan asam laktat yang menimbulkan rasa nyeri pada otot (Lazuardi, 2016). Dalam hal ini saraf yang berperan adalah nervus mendianus yang mempersarafi otot-otot fleksor di lengan bawah yang merupakan percabangan dari flexus brachialis bagian sistem saraf tepi yang keluar dari vertebra C5, C6, C7, C8 dan T1 (Snell, 2014).

Aktivitas yang dilakukan dengan frekuensi tinggi seperti gerakan berulang dapat menjadi faktor risiko timbulnya carpal tunnel syndrome (Selviyati, 2016). Faktor risiko yang juga menyebabkan terjadinya carpal tunnel syndrome yaitu adanya tekanan pada otot, getaran, suhu, sikap kerja yang tidak ergonomis (Kurniawan, 2008). Selain itu usia, cara kerja, dan peralatan kerja juga berkaitan dengan terjadinya carpal tunnel syndrome (Lusianawaty, 2012).

Berdasarkan studi pendahuluan yang telah dilakukan, diambil 5 orang secara acak untuk dijadikan sebagai sampel. Selanjutnya dilakukan wawancara dan observasi kepada sampel dari usia, masa kerja dan keluhan yang sering dirasakan sehingga didapatkan hasil 5 sampel mengalami keluhan nyeri, kesemutan dan kaku pada pergelangan tangan. Sampel 1 berusia 65 tahun dengan masa kerja > 20 tahun, sampel 2 berusia 47 tahun dengan masa kerja $<20$ tahun, sampel 3 berusia 50 tahun $>20$ tahun, sampel 4 berusia 52 tahun dengan masa kerja $>20$ tahun dan sampel 5 berusia 40 tahun dengan masa kerja $<20$ tahun. Dari hasil studi pendahuluan tersebut dapat menjadi faktor risiko terjadinya carpal tunnel syndrome. Pada pemeriksaan objektif didapatkan hasil vital sign berupa denyut nadi antara 72 kali per menit sampai 88 kali per menit dan tekanan darah antara 110/70 mmHg-130/80 $\mathrm{mmHg}$ sebelum bekerja. Kemudian dilakukan phalen's test yaitu tes yang baik untuk diagnosis carpal tunnel syndrome dan mendapatkan hasil positif carpal tunnel syndrome.
Keluhan pada carpal tunnel syndrome akan sangat mengganggu aktivitas kegiatan sehari-hari yang melibatkan fungsional tangan seperti menggenggam, menjepit dan sebagainya. Adanya keluhan tersebut dapat dikurangi dengan melakukan active stretching.

Stretching merupakan penguluran otot yang dilakukan untuk mempersiapkan otot tubuh dalam beraktivitas dan merileksasikan otot (Nohantiya, 2016). Peregangan aktif atau active stretching merupakan jenis prosedur peregangan yang lakukan secara mandiri setelah diberikan instruksi yang dilakukan tanpa mendapat bantuan dari kekuatan eksternal. (Kisner \& Colby, 2017). Peregangan yang dilakukan secara teratur diselasela pekerjaan dapat bermanfaat bagi tubuh yaitu, dapat mengurangi ketegangan otot, memperbaiki peredaran darah, mengurangi kecemasan, perasaan tertekan dan kelelahan, mengurangi risiko cidera dan membuat merasa lebih baik (Anderson, 2008).

\section{METODE PENELITIAN}

Rancangan penelitian ini adalah penelitian pre-eksperimental dengan rancangan satu kelompok dengan tes awal dan tes akhir (onegroup pretest-posttest design). Penelitian dilakukan di Desa Sidan Kabupaten Gianyar pada bulan 29 Mei hingga 16 Juni tahun 2017. Sampel pada penelitian ini sebanyak 15 orang dengan teknik pengambilan sampel secara purposive sampling sesuai dengan kriteria inklusi dan eksklusi.

Variabel terbagi menjadi dua yaitu variabel bebas active stretching pergelangan tangan dengan melakukan gerakan active stretching pergelangan tangan pada pergelangan tangan dan tahan masingmasing gerakan selama 7 detik dilakukan 5 sesi disetiap posisi serta dilakukan pada pagi hari saat akan bekerja dan pada saat istirahat kerja secara teratur 3 kali seminggu sedangkan variabel terikat yaitu keluhan carpal tunnel syndrome dengan melakukan pengisian kuesioner 11 pertanyaan dengan penilaian menggunakan skala Likert. Kemudian dilanjutkan dengan Phalen Test dilakukan dengan menekuk kedua tangan pada kedudukan fleksi secara maksimal selama 30 detik. Bila timbul rasa tebal aatau parestesia di daerah persarafan nervus medianus tes dinyatakan positif.

Data yang diperoleh oleh peneliti pada penelitian ini dianalisis untuk mengetahui pengaruh pemberian pemberian active stretching pergelangan tangan dapat mengurangi keluhan carpal tunnel syndrome pada pekerja pandai besi di Desa Sidan Kabupaten Gianyar menggunakan uji statistik yaitu Shapiro Wilk Test dan karena hasil berdistribusi normal $\mathrm{p} \geq 0,05$ data kembali diuji menggunakan uji paired t-test. 


\section{HASIL DAN PEMBAHASAN Distribusi karakteristik sampel Usia}

Data distribusi usia yang diperoleh pada penelitian ini, dapat dilihat pada tabel berikut:

Tabel 1. Usia Sampel

\begin{tabular}{cccc}
\hline No. & Usia & Frekuensi & Persentase (\%) \\
\hline 1. & $30-39$ th & 3 & 20 \\
2. & $40-49$ th & 6 & 40 \\
3. & $50-59$ th & 3 & 20 \\
4. & $60-69$ th & 3 & 20 \\
\hline & Jumlah & 15 & $100 \%$ \\
\hline
\end{tabular}

Berdasarkan Tabel 1 diketahui bahwa sampel kelompok usia 30-39 tahun berjumlah 3 orang dengan persentase $20 \%$, kelompok usia 4049 tahun berjumlah 6 orang dengan persentase 40\%, kelompok usia 50-59 tahun berjumlah 3 orang dengan persentase $20 \%$ dan kelompok usia 60-69 tahun berjumlah 3 orang dengan persentase $20 \%$.

\section{Masa kerja}

Data distribusi masa kerja yang diperoleh pada penelitian ini, dapat dilihat pada tabel berikut ini:

Tabel 2. Distribusi Masa Kerja Sampel

\begin{tabular}{cccc}
\hline No. & Masa kerja & Frekuensi & $\begin{array}{c}\text { Persentase } \\
(\%)\end{array}$ \\
\hline 1. & $<20$ tahun & 7 & $46,7 \%$ \\
2. & $>20$ tahun & 8 & $53,3 \%$ \\
\hline & Jumlah & 15 & $100 \%$ \\
\hline
\end{tabular}

Berdasarkan Tabel 2 diketahui bahwa sampel kelompok masa kerja $<20$ tahun berjumlah 7 orang dengan persentase $46,7 \%$ dan kelompok masa kerja $>20$ tahun berjumlah 8 orang dengan persentase $53,3 \%$.

\section{Kategori keluhan carpal tunnel syndrome}

Data distribusi ketegori keluhan carpal tunnel syndrome pada penelitian ini, dapat dilihat pada tabel berikut:

Tabel 3. Distribusi Kategori Keluhan Carpal Tunnel Syndrome

\begin{tabular}{ccc}
\hline \multirow{2}{*}{ Kategori } & \multicolumn{2}{c}{ Pretest } \\
\cline { 2 - 3 } & Frekuensi & Persentase (\%) \\
\hline Ringan & 0 & 0 \\
Sedang & 11 & 73.3 \\
Berat & 4 & 26.7 \\
\hline Total & 15 & 100 \\
\hline
\end{tabular}

Berdasarkan Tabel 3 distribusi keluhan carpal tunnel syndrome diketahui bahwa sampel dengan kategori ringan berjumlah 0 dengan presentase $0 \%$, sampel dengan kategori sedang berjumlah 11 dengan presentase $73,3 \%$ dan sampel dengan kategori berat berjumlah 4 dengan presentase $26,7 \%$.

\section{Hasil penelitian sebelum dan sesudah pemberian active stretching pergelangan tangan \\ Berdasarkan hasil penelitian yang sudah dilakukan, tingkat keluhan yang dirasakan responden sebelum dan sesudah diberikan latihan active stretching pergelangan tangan dapat dilihat pada tabel berikut:}

Tabel 4. Hasil Penelitian Sebelum (Pretest) dan Sesudah (Posttest) Pemberian Active Stretching Pergelangan Tangan

\begin{tabular}{ccc}
\hline Parameter & Pretest & Posttest \\
\hline N & 15 & 15 \\
Mean & 33,60 & 27,00 \\
Median & 33,00 & 27,00 \\
Minimum & 26,00 & 20,00 \\
Maximum & 40,00 & 32,00 \\
\hline
\end{tabular}

Berdasarkan hasil data di atas, diperoleh bahwa sebelum pemberian active stretching pergelangan tangan yang dirasakan sampel adalah keluhan dengan kategori sedang. Dilihat dari nilai mean 33,60 , nilai median 33,00 , nilai minimum 26,00 dan nilai maximum 40,00. Sesudah pemberian active stretching pergelangan tangan yang dirasakan sampel adalah keluhan dengan kategori sedang, dimana nilai mean 27,00 , nilai median 27,00, nilai minimum 20,00 dan nilai maximum 32,00. Maka dari hasil tersebut diperoleh bahwa terjadi penurunan keluhan yang dirasakan sampel dilihat dari nilai mean dengan selisih 6,60.

\section{Uji normalitas data}

Tabel 5. Hasil Uji Normalitas Data Keluhan Carpal Tunnel Syndrome

\begin{tabular}{lcc}
\hline \multirow{2}{*}{\multicolumn{1}{c}{ Data }} & \multicolumn{2}{c}{ Shapiro-Wilk } \\
\cline { 2 - 3 } & Sig. & Intepretasi \\
\hline $\begin{array}{l}\text { Sebelum active } \\
\text { stretching pergelangan } \\
\text { tangan (pre-test) }\end{array}$ & 0.391 & Normal \\
$\begin{array}{l}\text { Sesudah active } \\
\text { stretching pergelangan } \\
\text { tangan (post-test) }\end{array}$ & 0.443 & Normal \\
\hline
\end{tabular}

Dari hasil uji normalitas di atas, signifikansi dari data sebelum active stretching pergelangan 
tangan (pretest) adalah 0.391 dan signifikansi dari data sesudah active stretching pergelangan tangan (posttest) adalah 0.443 , sehingga kedua data tersebut dapat dikatakan berdistribusi normal karena tingkat signifikasi lebih dari 0,05.

\section{Uji hipotesis}

Table 6. Hasil Analisis Uji t Berpasangan (Paired t-Test)

\begin{tabular}{|c|c|c|c|c|c|c|c|}
\hline \multirow{2}{*}{ Data } & \multirow[b]{2}{*}{ Mean } & \multirow[b]{2}{*}{$\mathrm{N}$} & \multicolumn{5}{|c|}{ Uji Paired t-test } \\
\hline & & & $\begin{array}{c}\text { Mean } \\
\text { d }\end{array}$ & $\mathrm{T}_{\text {hitung }}$ & $\mathrm{df}$ & $\mathrm{T}_{\text {tabel }}$ & Sig. \\
\hline Sebelum & 33,6 & & & & & & \\
\hline Sesudah & 27 & 15 & 6,60 & 18,903 & 14 & 2,145 & 0,000 \\
\hline
\end{tabular}

Berdasarkan tabel 6, rata-rata yang didapat sebelum pemberian active stretching pergelangan tangan (pretest) adalah 33,60 dan untuk rata-rata sesudah pemberian active stretching pergelangan tangan (posttest) adalah 27. Uji hipotesis berdasarkan perbandingan t-hitung dengan t-tabel dimana nilai t-hitung adalah 18.903 dan t-tabel adalah 2,145. Berdasarkan df atau derajat kebebasan dimana n-1 yaitu 15-1 = 14 sehingga pada $t$ tabel didapat angka 2,145.

Jadi, berdasarkan perbandingan $\mathrm{t}$ hitung dengan t-tabel yaitu $18.903>2,145$ maka $\mathrm{H}_{0}$ ditolak dan $\mathrm{H}_{\mathrm{a}}$ diterima dan pada hasil signifikan 0,000 yang artinya $0,000<0,05$ menyatakan bahwa pemberian active stretching pergelangan tangan dapat mengurangi keluhan carpal tunnel syndrome pada pekerja pandai besi di Desa Sidan Kabupaten Gianyar.

\section{Pembahasan}

Pada umumnya keluhan muskuloskeletal mulai dirasakan pada umur 30 tahun dan semakin meningkat pada umur 40 tahun ke atas. Hal ini disebabkan perubahan biologis secara alamiah pada

Berdasarkan hasil penelitian yang dilakukan oleh Ristiyanto (2015) dinyatakan ada perbedaan nyeri sendi sebelum dan sesudah stretching di Unit Rehabilitasi Sosial Pucang Gading Semarang. Terapi latihan peregangan atau stretching bermanfaat selain dapat menurunkan nyeri juga dapat mengembalikan kelenturan otot-otot yang mengalami kekakuan. Stretching itu sendiri dapat membuat otot tetap lentur, kesiapan otot untuk bergerak dalam melakukan aktivitas tanpa menimbulkan ketegangan (Mujianto, 2013). Mekanisme stretching termasuk dalam kategori stimulasi mekanik yang dapat mengaktivasi fungsi serabut saraf berpenampang tebal non-nociceptif (A alpha dan A beta) dan menutup gerbang kontrol sehingga nyeri yang dibawa serabut saraf berpenampang tipis (A delta dan C) tidak dapat diteruskan ke otak (Rovitri, 2015). Dengan latihan usia paruh baya kekuatan dan ketahanan otot mulai menurun karena proses penuaan, misalnya degeneratif otot, tendon, ligamen dan sendi sehingga risiko terjadinya keluhan meningkat (Rahayu, 2012).

Pada penelitian ini diketahui masa kerja pekerja pandai besi di Desa Sidan Kabupaten Gianyar dapat dilihat pada Tabel 2. Menurut penelitian yang dilakukan oleh Cris (2012) memperoleh hasil ada hubungan antara masa kerja dengan sindrom terowongan karpal pada pembatik di CV. Pusaka Beruang Lasem. Masa kerja > 4 tahun dapat menyebabkan stress disekitar jaringan terowongan karpal dan akan menyebabkan sindrom terowongan karpal.

Berdasarkan hasil uji hipotesis dengan menggunakan uji $\mathrm{t}$ berpasangan (paired t-test) yaitu perbandingan $\mathrm{t}$ hitung dengan $\mathrm{t}$ tabel yaitu $18.903>2,145$ maka $\mathrm{H}_{0}$ ditolak dan $\mathrm{H}_{\mathrm{a}}$ diterima. Pada hasil signifikan 0,000 yang artinya $0,000<$ 0,05 menyatakan bahwa pemberian stretching pergelangan tangan dapat mengurangi keluhan carpal tunnel syndrome pada pekerja pandai besi di Desa Sidan Kabupaten Gianyar.

peregangan dapat mengurangi gejala kekurangan oksigen sel yang dapat menyebabkan peningkatan asam laktat sehingga menimbulkan nyeri (Nurdiati $\mathrm{dkk}, 2015)$. Pemberian tendon strech dan nerve gliding yang dilakukan oleh Kaur (2016) selama 3 minggu menunjukkan bahwa latihan ini baik dilakukan untuk carpal tunnel syndrome. Dan tidak ada perbedaan terhadap penurunan nyeri carpal tunnel syndrome dengan pemberian tendon strech yang sasarannya pada tendon dan pemberian neural mobilisasi yang sasarannya pada saraf karena memiliki tujuan yang sama yaitu meningkatkan sirkulasi darah pada pergelangan tangan sehingga meningkatkan perbaikan pada jaringan lunak (Nur, 2015). 


\section{KESIMPULAN}

Berdasarkan uji hipotesis terdapat perbedaan yang bermakna pada keluhan carpal tunnel syndrome sebelum dan sesudah diberikan active stretching pergelangan tangan. Jadi, dapat disimpulkan bahwa pemberian active stretching pergelangan tangan dapat mengurangi keluhan nyeri pergelangan tangan akibat carpal tunnel syndrome pada pekerja pandai besi di Desa Sidan Kabupaten Gianyar.

\section{DAFTAR PUSTAKA}

Anderson, 2008. Stretching in The Office. Serambi Ilmu Semesta. Jakarta

Guyton, Hall. 2007. Buku Ajar Fisiologi Kedokteran, Edisi 11. Jakarta: EGC

Kaur dkk. 2016. Effect of Tendon and Nerve Gliding In Carpal Tunnel Syndrome: Clinical and Electrophysiological Examination. International Journal of Healthcare Sciences Volume 4 Nomor 1. India

Kisner, Colby. 2017. Terapi Latihan Dasar dan Teknik Volume 2 Edisi 6. Jakarta : ECG

Kurniawan, 2008. Faktor Risiko Kejadian Carpal Tunnel Syndrome (CTS) Pada Wanita Pemetik Melati Di Desa Karangcengis, Purbalingga. Jurnal Promosi Kesehatan Indonesia Volume 3 Nomor 1, Januari 2008

Lazuardi, Ahmad Iqbal. 2016. Determinan Gejala Carpal Tunnel Syndrome (CTS) pada Pekerja Pemecah Batu di Kecamatan Sumbersari dan Sukowono Kabupaten Jember. Skripsi Sarjana. Bagian Kesehatan Lingkungan dan Kesehatan Keselamatan Kerja Fakultas Kesehatan Masyarakat Universitas Jember.

Lusianawaty. 2012. Peran Latihan Tangan Dalam Pencegahan Carpal Tunnel Syndrome Pada Perempuan Pekerja Garmen. Jurnal Ekologi Kesehatan Volume 11 Nomor 2, Juni 2012

Mujianto. 2013. Cara Praktis Mengatasi Nyeri Leher dan Nyeri Pinggang dalam Stretching Seri Fisioterapi. Jakarta:Trans Info Media.

Nohantiya. 2016. Pengembangan VCD Instruksional Peregangan Aktif (Active Stretching) Kesegaran Jasmani Siswa SMP di Malang. Jurnal Multilateral Volume 15 Nomor 2. Malang

Nur. 2015. Perbedaan Pemberian Ultrasound dengan Tendo Stretch dan Pemberian Ultrasound dengan Neural Mobilisasi Terhadap Penurunan Nyeri Carpal Tunnel Syndrome. Naskah Publikasi. Program Studi Fisioterapi Sekolah Tinggi Ilmu Kesehatan Aisyiyah Yogyakarta
Nurdiati dkk. 2015. Pengaruh Peregangan Terhadap Penurunan Intensitas Nyeri pada Perawat yang Menderita Low Back Pain $(L B P)$. JOM Volume 2 Nomor 1. Riau

Rahayu, W.A. 2012. Faktor-faktor yang Berhubungan dengan Keluhan Muskuloskeletal pada Pekerja AngkatAngkut Industri Pemecahan Batu Di Kecamatan Karangnongko Kabupaten Klaten. Jurnal Kesehatan Masyarakat, Volume 1, Nomor 2, Tahun 2012

Rina. 2010. Hubungan Repetitive Motion dengan Keluhan Carpal Tunnel Syndrome pada Pekerjaan Menjahit di Bagian Konveksi PT. Dan Laris Sukoharjo. Skripsi Sarjana. Fakultas Kedokteran Sebelas Maret Surakarta

Ristiyanto, Iik. 2015. Efektifitas Latihan Peregangan Otot (Stretching) dan Kompres Hangat Terhadap Nyeri Sendi pada Lansia di Unit Rehabilitasi Sosial Pucang Gading Semarang. Program Studi S1 Keperawatan Fakultas Ilmu Keperawatan dan Kesehatan Universitas Muhamaddiyah Semarang. [diakses 24 Juli 2017]

Rovitri, 2015. Perbedaan Keluhan Muskuloskeletal Sebelum Dan Sesudah Pemberian Workplace Stretching-Exercise Pada Perawat Di Rsia Badrul AiniMedan Tahun 2015. Naskah Publikasi.

Selviyati V, Camelia A, Sunarsih E. 2016. Analisis Determinan Kejadian Carpal Tunnel Syndrome (Cts) Pada Petani Penyadap Pohon Karet Di Desa Karang Manik Kecamatan Belitang Ii Kabupaten Oku Timur. Jurnal Ilmu Kesehatan Masyarakat Volume 7 Nomor 3

Snell. 2014. Neuroanatomi Klinik Edisi 7. Jakarta: ECG

Suherman, B. 2012. Beberapa Faktor Kerja yang Berhubungan dengan Kejadian CTS pada Petugas Rental Komputer di Kelurahan Kahuripan Kota Tasikmalaya. Skripsi Sarjana. Universitas Siliwangi.

Suma'mur P.K. 2014. Kesehatan Kerja dalam Perspektif Hiperkes dan Keselamatan Kerja. Jakarta: Erlangga

Syaifuddin. 2013. Anatomi Fisiologi Kurikulum Berbasis Kompetensi Untuk Keperawatan \& Kebidanan, Ed. 4. Jakarta: Penerbit Buku Kedokteran EGC.

Zuhri, dkk. 2012. Latihan Neural Stretching Dan Penurunan Nyeri Penderita Carpal Tunnel Syndrome. Jurnal Terpadu Ilmu Kesehatan, Jilid 1. Surakarta 